\title{
Video-assisted thoracoscopic surgery lobectomy: transitions in practice
}

\author{
Andrew P. Dhanasopon, Daniel J. Boffa \\ Section of Thoracic Surgery, Department of Surgery, Yale School of Medicine, New Haven, CT, USA \\ Correspondence to: Andrew P. Dhanasopon, MD. 330 Cedar St. BB205, PO Box 208062, New Haven, CT 06520-8062, USA. \\ Email: andrew.dhanasopon@yale.edu. \\ Provenance: This is an invited Editorial commissioned by the Section Editor Laura Chiara Guglielmetti (Cantonal Hospital Winterthur, Kantonsspital \\ Winterthur, Winterthur, Switzerland). \\ Comment on: Divisi D, Barone M, Zaccagna G, et al. Video-assisted thoracoscopic surgery lobectomy learning curve: what program should be offered \\ in a residency course? J Vis Surg 2017;3:143.
}

Submitted Aug 20, 2018. Accepted for publication Sep 11, 2018.

doi: $10.21037 /$ jtd.2018.09.44

View this article at: http://dx.doi.org/10.21037/jtd.2018.09.44

Video-assisted thoracoscopic surgery (VATS) is widely accepted as a standard approach for the surgical treatment of stages I and II non-small cell lung cancers (NSCLC) (1). Two meta-analyses (2,3), four large United States database studies (4-7), and several retrospective single-institution studies (8-13) have demonstrated that VATS lobectomy is associated with fewer complications (pulmonary, atrial fibrillation), transfusion rate, pain, and length of hospital stay without compromising oncologic outcomes when matched for stage. Despite the benefits of VATS compared to thoracotomy, the adoption of this technique has progressed slowly, with only $44 \%$ of lobectomies being performed by VATS in the U.S. in 2014 (14) and only 27\% in Europe (15).

As noted in Divisi et al.'s review (16), the hesitation for practicing surgeons to adopt VATS likely stems from reticence in transitioning out of the standard open technique due to preconceived notions of the complexity, length of the procedure, and difficulty in managing catastrophic complications. In addition, one could argue that learning a new surgical technique is not worth the lost time and pay for surgeons whose skill and practice have afforded their patients good outcomes already. Thus, in the face of increasingly favorable evidence and urgency for practicing thoracic surgeons to develop minimally-invasive techniques, there has been considerable effort in developing ways to shorten the learning curve to perform VATS lobectomy proficiently for practicing surgeons and surgical trainees.
McKenna suggests the length of the learning curve consists of 50 lobectomies to achieve proficiency (17). Included in this learning curve are cognitive and manual skill development. The ability to reliably correlate the twodimensional VATS image with prior knowledge of threedimensional anatomy from the open technique is essential to safe and effective VATS surgery. For the practicing open surgeon, already having this mastery of anatomy is a clear advantage, but the translation of images from two- to threedimensional anatomy, then making decisions within a twodimensional space is a major part of the cognitive learning curve.

The manual skills of the learning curve include port placement, tissue retraction and handling, and dissection, energy, and stapling techniques. Many atlases (18) and online resources (19) are available that detail how to perform the operation. Additionally, there are courses offered by professional societies and industry. Case observation with a surgeon regularly performing VATS lobectomy is likely the most beneficial and time-efficient. Once these manual skills are learned, case volume and case frequency are essential in the maintenance and progression of the learning curve. To this end, there has been considerable development of VATS lobectomy simulators.

The introduction of VATS lobectomy simulators has theoretical advantage of shortening the time required to attain the cognitive and manual skills required for learning curve. In 2010, Meyerson et al. reported on a simple, 
low cost porcine heart-lung tissue block that allowed participants to identify vessel injuries or other errors, though the vessels were inherently easier to identify due to the absence of significant lymph nodes (20). In formal VATS courses sponsored by industry, high fidelity simulations using anesthetized pigs are used which are effective for procedural learning, but are limited by high cost and are single-use.

Virtual reality (VR) simulators are increasingly becoming a popular tool in surgical education (21). In the U.S., there is ongoing discussion about whether the instituted reduction in work hours of surgical trainees will correlate with reduction in clinical experience and cases. VR simulators would allow trainees to practice before surgery to improve the cognitive and procedural skills that will make their time in the operating room more effective and efficient learning environment, potentially leading to better patient safety as well. In 2014, Jensen et al. (22) included 28 surgical trainees with minimal experience in VATS (less than three supervised procedures) and randomized them into black-box (porcine) $v s$. VR groups. All participants trained to a predefined scenario in an abdominal model without any time limit. After procedural completion, overall skill acquisition was evaluated according to time and errors. Surprisingly, the black-box group was significantly faster than VR group both with and without time penalty (26.6 vs. $32.7 \mathrm{~min}, \mathrm{P}=0.032$ and 29.6 vs. $35.5 \mathrm{~min}, \mathrm{P}=0.043$, respectively). In addition, no difference in bleeding and anatomical errors were found. The authors concluded that the lack of tactile feedback in VR simulation group, i.e., the lack of ability to feel tissue with real instruments and apply the correct required forces, was a significant drawback to the VR simulator. Today, the only dedicated VATS VR simulator (LapSim ${ }^{\circledR}$, Surgical Science, Göteborg, Sweden) provides simulated practice with hilum dissection, vessel identification, vascular and bronchial stapling, and bleeding control (and thus dexterity acquisition) but it only simulates a right upper lobectomy, and its cost and maintenance limit its adoption.

While simulators reinforce the cognitive and manual skills required to progress on the learning curve, other less tangible elements are equally important in developing a VATS practice. Judgement in knowing when and how to convert to open thoracotomy and when to call for assistance, are essential to keeping the patient safe. Having partners in practice who also perform VATS lobectomy allows the surgeon to mature these skills in a VATSsupportive environment.
The advent of robotic-assisted thoracoscopic surgery adds another complexity to the development of the thoracic surgeon. Robotic technology is an evolution of VATS, developed to overcome some of the limitations of VATS including bi-dimensional vision, camera and retraction being under the assistant's control, and limited range of motion (23). The robotic da Vinci system ${ }^{\circledR}$ (Sunnyvale, CA, USA) consists of a master console used by the surgeon that connects via optic fibers and electrical cables to a patient cart with three instrument arms and a camera arm. The $3 \mathrm{D}$ high definition camera gives to the surgeon a much-improved vision compared to VATS. The surgeon's movements and any physiologic tremors $(6-\mathrm{Hz}$ motion filter) are transmitted to the patient cart to manipulate the instruments. The robotic instruments, with seven degrees of freedom, allow the replication of the human wrist movement. However, it remains to be seen if there are any clinically relevant advantages of robotic-assisted lobectomies over VATS. Unless in specialized centers with expert robotic surgeons, at this time most robotic lobectomies have longer operative times and higher costs with similar patient-centered outcomes. There is some evidence that the robotic platform provides a reduced learning curve from open surgery, compared to VATS, however, the data is still premature (24).

Regardless of the acquired minimally-invasive technique, the pendulum has clearly moved away from open lobectomies, given the wealth of evidence for improved patient outcomes with VATS lobectomy. Learning curves in the acquisition and maintenance of cognitive and manual skills required for VATS lobectomy can be reduced with the assistance of course instruction, case observations, and even simulators, but ultimately, requires the commitment of the surgeon and his/her practice environment.

\section{Acknowledgements}

None.

\section{Footnote}

Conflicts of Interest: The authors have no conflicts of interest to declare.

\section{References}

1. Howington JA, Blum MG, Chang AC, et al. Treatment of stage I and II non-small cell lung cancer: Diagnosis and 
management of lung cancer, 3rd ed: American College of Chest Physicians evidence-based clinical practice guidelines. Chest 2013;143:e278S-313S.

2. Cheng D, Downey RJ, Kernstine K, et al. Video-assisted thoracic surgery in lung cancer resection: a meta-analysis and systematic review of controlled trials. Innovations (Phila) 2007;2:261-92.

3. Yan TD, Black D, Bannon PG, et al. Systematic review and meta-analysis of randomized and nonrandomized trials on safety and efficacy of video-assisted thoracic surgery lobectomy for early-stage non-small-cell lung cancer. J Clin Oncol 2009;27:2553-62.

4. Farjah F, Wood DE, Mulligan MS, et al. Safety and efficacy of video-assisted versus conventional lung resection for lung cancer. J Thorac Cardiovasc Surg 2009;137:1415-21.

5. Paul S, Altorki NK, Sheng S, et al. Thoracoscopic lobectomy is associated with lower morbidity than open lobectomy: a propensity-matched analysis from the STS database. J Thorac Cardiovasc Surg 2010;139:366-78.

6. Park HS, Detterbeck FC, Boffa DJ, et al. Impact of hospital volume of thoracoscopic lobectomy on primary lung cancer outcomes. Ann Thorac Surg 2012;93:372-9.

7. Boffa DJ, Kosinski AS, Furnary AP, et al. Minimally Invasive Lung Cancer Surgery Performed by Thoracic Surgeons as Effective as Thoracotomy. J Clin Oncol 2018;36:2378-85.

8. Whitson BA, Andrade RS, Boettcher A, et al. Videoassisted thoracoscopic surgery is more favorable than thoracotomy for resection of clinical stage I non-small cell lung cancer. Ann Thorac Surg 2007;83:1965-70.

9. Flores RM, Park BJ, Dycoco J, et al. Lobectomy by videoassisted thoracic surgery (VATS) versus thoracotomy for lung cancer. J Thorac Cardiovasc Surg 2009;138:11-8.

10. Villamizar NR, Darrabie MD, Burfeind WR, et al. Thoracoscopic lobectomy is associated with lower morbidity compared with thoracotomy. J Thorac Cardiovasc Surg 2009;138:419-25.

11. Scott WJ, Allen MS, Darling G, et al. Video-assisted thoracic surgery versus open lobectomy for lung cancer: a secondary analysis of data from the American College of Surgeons Oncology Group Z0030 randomized clinical trial. J Thorac Cardiovasc Surg 2010;139:976-81; discussion 981-3.

12. Ilonen IK, Räsänen JV, Knuuttila A, et al. Anatomic thoracoscopic lung resection for non-small cell lung cancer in stage $\mathrm{I}$ is associated with less morbidity and shorter hospitalization than thoracotomy. Acta Oncol 2011;50:1126-32.

13. Handy JR Jr, Asaph JW, Douville EC, et al. Does videoassisted thoracoscopic lobectomy for lung cancer provide improved functional outcomes compared with open lobectomy?. Eur J Cardiothorac Surg 2010;37:451-5.

14. Blasberg JD, Seder CW, Leverson G, et al. Video-Assisted Thoracoscopic Lobectomy for Lung Cancer: Current Practice Patterns and Predictors of Adoption. Ann Thorac Surg 2016;102:1854-62.

15. The ESTS 2017 Silver Book. Available online: http://www. ests.org/_userfiles/pages/files/database_reports/ESTS\%20 2017\%20Silver\%20Book\%20Full\%20Version.pdf

16. Divisi D, Barone M, Zaccagna G, et al. Video-assisted thoracoscopic surgery lobectomy learning curve: what program should be offered in a residency course? J Vis Surg 2017;3:143.

17. McKenna RJ Jr. Complications and learning curves for video-assisted thoracic surgery lobectomy. Thorac Surg Clin 2008;18:275-80.

18. McKenna RJ, Mahtabifard A, Swanson SJ. Atlas of Minimally Invasive Thoracic Surgery (VATS), 1st Ed. Saunders, 2011.

19. VATS Lobectomy for Early Stage Lung Cancer. Available online: https://www.ctsnet.org/article/vats-lobectomyearly-stage-lung-cancer

20. Meyerson SL, LoCascio F, Balderson SS, et al. An inexpensive, reproducible tissue simulator for teaching thoracoscopic lobectomy. Ann Thorac Surg 2010;89:594-7.

21. Petersen RH, Hansen HJ. Learning curve associated with VATS lobectomy. Ann Cardiothorac Surg 2012;1:47-50.

22. Jensen K, Ringsted C, Hansen HJ, et al. Simulationbased training for thoracoscopic lobectomy: a randomized controlled trial: virtual-reality versus black-box simulation. Surg Endosc 2014;28:1821-9.

23. Ricciardi S, Cardillo G, Zirafa CC, et al. Robotic lobectomies: when and why? J Vis Surg 2017;3:112.

24. Liang H, Liang W, Zhao L, et al. Robotic Versus Videoassisted Lobectomy/Segmentectomy for Lung Cancer: A Meta-analysis. Ann Surg 2018;268:254-9.

Cite this article as: Dhanasopon AP, Boffa DJ. Video-assisted thoracoscopic surgery lobectomy: transitions in practice. J Thorac Dis 2018;10(Suppl 33):S3834-S3836. doi: 10.21037/ jtd.2018.09.44 